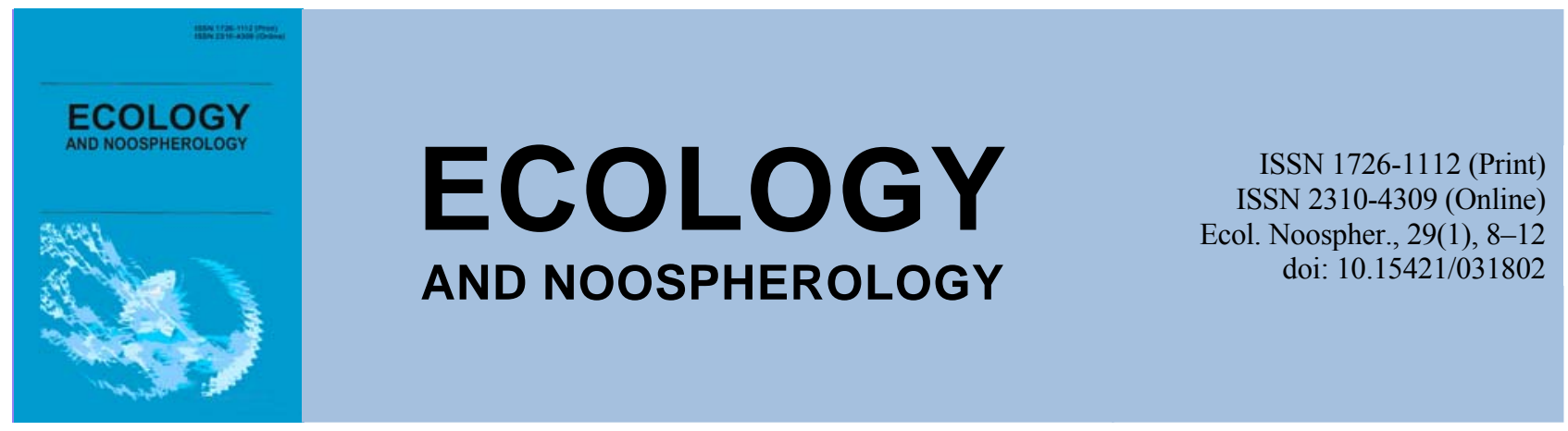

\title{
Radiation situation in typical mining-processing agglomerations of the Dnepropetrovsk region
}

\author{
O. O. Shugurov, A. V. Knyazyuk \\ Oles Honchar Dnipro National University, Dnipro, Ukraine
}

Article info

Received 10.03.2018

Received in revised form

18.03 .2018

Accepted 23.03.2018

Oles Honchar Dnipro

National University

Gagarin Ave., 72, Dnipro,

49010, Ukraine.

Tel.: +38-066-509-44-99

E-mail: oshugurov@gmail.com

\begin{abstract}
Shugurov, O. O., \& Knyazyuk, A. V. (2018). Radiation situation in typical mining-processing agglomerations of the Dnepropetrovsk region. Ecology and Noospherology, 29(1), 8-12. doi:10.15421/031802
\end{abstract}

The existing agglomeration of mining and processing enterprises in the Dnipropetrovsk region of Ukraine can significantly influence on the radiation situation in the nearest small working cities. The purpose of the work was to determine the level of radiation pollution in the territory of the city Pokrov of the Dnipropetrovsk region, originating from mining waste rock at local enterprises. In the work we used profile reconnaissance. Radiation background measurements were made at equal distances along straight lines. The working measurement step corresponded to an average value of $300 \mathrm{~m}$. During the research, 259 measurements in the $\gamma$-range were made. Studies covered a total area of about $25 \mathrm{~km}^{2}$ (an average of 16 measurements per $1 \mathrm{~km}$ ). For the accurately adjust the measurement location and then transfer the results to the map, a GPS tracker was used. It was revealed that the greatest radiation contamination in the investigated area was recorded on the territory of Tokovsky spillway, where flooded quarries for the extraction of red granites $(50 \mu \mathrm{R} / \mathrm{h}$ and above) are located. The territories of all working quarries exhibit an increased radiation background $(17-21 \mu \mathrm{R} / \mathrm{h})$, with maximum values $(30-35 \mu \mathrm{R} / \mathrm{h})$ on their lower horizons. This increase is due to small outcrops of granite in some formations, as well as places for direct mining of manganese ore. A slight increase in the background relative to residential areas (from 13 to $20 \mu \mathrm{R} / \mathrm{h}$ ) was noted at the ore-dressing and slurry storages, but still it remains at an acceptable level, which does not affect the city's population working here. The radiation background in the area of city Pokrov and adjacent villages, reclaimed lands and agricultural fields has a low level $(5-7 \mu \mathrm{R} / \mathrm{h}$ ). A number of city points (roads and a bridge across the Bazavluk River, monuments) showed pollution at a level of $10-15 \mu \mathrm{R} / \mathrm{h}$. This is due to the use of local natural materials in their construction. Thus, the overall radiation situation in the city of Pokrov and the agglomeration of ore mining and processing enterprises at the present time can be assessed as satisfactory by modern criteria.

Keywords: radiation situation; gamma-radiation; mining and processing enterprises

\section{Радиационная обстановка в типичных горнообогатительных агломерациях Днепропетровской области}

\author{
О. О. Шугуров, А. В. Князюк
}

Днепровский нацииональный университет имени Олеся Гончара, Днепр, Украина

Существующие в Днепропетровской области агломерации горнообогатительных предприятий способны существенно влиять на радиационную обстановку в прилегающих к ним маленьких рабочих городах. Целью работы стало определение уровня радиационного загрязнения территории города Покров Днепропетровской области, происходящего от отходов горных пород на местных предприятиях. В работе применяли профильную разведку: производили измерения радиационного фона на равных расстояниях вдоль прямых линий. Рабочий шаг измерения соответствовал среднему значению в 300 м. Всего в процессе исследований было сделано 259 радиационных измерений в $\gamma$-диапазоне излучений, которые охватили общую площадь около 25 км ${ }^{2}$ (в среднем 16 измерений на 1 км). Для точной корректировки места измерения и переноса полученных результатов на карту был использован GPS-трекер. Наибольшее радиационное загрязнение в исследуемом районе отмечено на территории Токовских водосбросов, где расположены затопленные карьеры по добыче красных гранитов (50 мкР/ч и выше). Территории всех работающих 
карьеров проявляют повышенный радиационный фон (17-21 мкР/ч), причем на их нижних горизонтах отмечены максимальные значения (30-35 мкР/ч). Такое повышение связано с небольшими выходами гранита на некоторых пластах, а также местами прямой добычи марганцевой руды. На горнообогатительных фабриках и шламохранилищах отмечено небольшое повышение фона относительно жилых территорий (от 13 до 20 мкР/ч), но все-таки он остается на допустимом уровне, не влияющем на работающее здесь население города. Радиационный фон на территории города Покров, прилежащих сел, рекультивированных земель и на сельскохозяйственных полях имеет низкий уровень (5-7 мкР/ч). В ряде точек города (дороги, мост через реку Базавлук, памятники) обнаружено загрязнение на уровне 10-15 мкР/ч, что связано с использованием при их строительстве местных природных материалов. Таким образом, общую радиационную ситуацию на территории города Покров и агломерации горнообогатительных предприятий на данный момент по современным критериям можно оценить как удовлетворительную.

Ключевые слова: радиационная ситуация; гамма-излучение; горнообогатительные предприятия

\section{Введение}

Долгое время считалось, что основным источником природного ионизирующего излучения являются горные породы и космос. Уровни земной радиации в различных регионах всегда были неодинаковыми. Районы месторождений фосфоритов или кристаллических пород, железных, марганцевых, урановых руд, радиоактивных сланцев, ториевых песков, радоновых минеральных источников отличаются по характеру и распределению на поверхности планеты, как следствие - существенно отличается и природный радиационный фон в таких местах (Galperin, 2010; Kovalenko, Voloshin, 2010).

В соседних с Украиной странах производится постоянный мониторинг радиационного загрязнения в местах, где осуществляются горнопромышленные работы (Lebedev, 2012; Ryabtseva, 2015). Выявлены подобные аномальные районы и в Днепропетровской области Украины: г. Желтые Воды, г. Кривой Рог, г. Ингулец, г. Марганец, г. Покров (бывший Орджоникидзе). В этих местах выхода на поверхность полезных ископаемых естественный фон в десятки (а иногда и сотни) раз выше, чем в соседних. Это вызвано повышенной миграцией изотопа из почв, которые разрабатываются открытым и закрытым способом, и из отработок (шламов) горнообогатительных комбинатов (Landa, 2004; Sokolov, 2005).

Промышленный г. Покров является типичным представителем территорий Днепропетровской области, включающих в себя агломерацию как горнообогатительных комбинатов, так и расположенных между ними районов, в которых проживает работающее на производстве население. Радиационные загрязнения от отходов горных пород являются типичными для малых промышленных городов Днепропетровской области и требуют постоянной оценки, чему и посвящена данная работа.

\section{Материалы и методы исследования}

В процессе работы были проведены полевые радиоизмерительные методы изучения экологической обстановки в исследуемом районе, уровня влияния на человека и окружающую среду природных и антропогенных геофизических факторов (Kharchenko, 2011). В наших исследованиях для измерения фона был использован дозиметрический рентгенметр ДП-5В (Vishnyakov, Mishnev, 2013), предназначенный для измерения значений гаммарадиации, а также радиоактивной зараженности различных почв и предметов.

В зависимости от поставленных задач изначально применяли профильную разведку. В таком случае производится измерение радиационного фона на равных расстояниях вдоль одной прямой линии (профиля), каждая точка в котором называется пикетом (Gablin et al., 2012). Также в процессе работы проводили площадную съемку (измерение радиационного фона по всей исследуемой площади по равномерной сетке) в соответствии с существующими картографическими методами (Romashova et al., 2012; Lebedev, 2012).

Рабочий шаг (расстояние между пикетами профиля и между самими профилями) выбирали в соответствии с размером исследуемой территории и необходимой степенью детализации распределения - он соответствовал среднему значению в 300 м. При выборе данного шага учитывали, что данные, полученные с большой детализацией, имеют большую ценность.

Всего в процессе исследований было сделано 259 радиационных измерений в $\gamma$-диапазоне излучений,

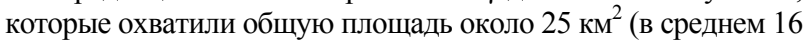
измерений на 1 км). Для точной корректировки места измерения и последующего переноса полученных результатов на карту был использован GPS-трекер. Так как большинство измерений проходили в открытых карьерах, то рабочий шаг на карте не был абсолютно равным.

Результаты проведения полевых измерений радиационного фона подвергали статистической обработке с использованием программного средства Statistica v.6.0.

\section{Результаты исследования и обсуждение}

В обследованные территории входили: город Покров с рядом рабочих поселков, 5 рабочих карьеров и один нерабочий, 3 горнообогатительные фабрики, каскад Токовских водопадов, на котором находятся открытые выходы гранита. После внесения всех измерений данные по 20 зонам были представлены в виде табл. 1, вычислены средние значения радиационного состояния на местности и на основе этих данных сделана карта распределения радиационного загрязнения естественными изотопами на обследованной местности (рис. 1).

Рассмотрим специфику радиационного загрязнения в обследованных зонах, прилегающих к городу Покров (усредненные радиометрические данные представлены в табл. 1).

\section{Таблица 1}

Средний природный фон обследованной территории вблизи г. Покров

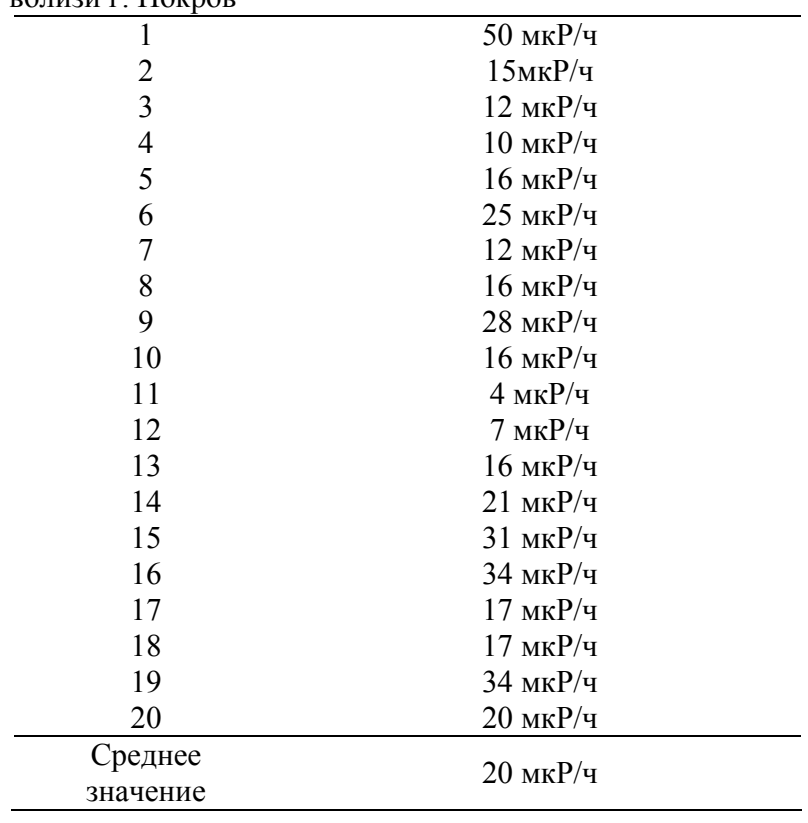


Зона № 1. Каскад Токовских водосбросов. Высокий уровень радиационного загрязнения в данной зоне связан с выходом на поверхность гранитных пород, которые имеют второй уровень радиационного излучения (самый высокий показатель в районе города Покров).

Зона № 2. Шламохранилище Александровской агломерационной фабрики. Средний фон составляет 15 мкР/ч, который связан со значительным содержанием частиц марганца, гранита.

Зона № 3. Рекультивированная земля, ранее использованная для нужд горнообогатительных комбинатов. В данной местности радиационный фон находится в норме, незначительное повышение его проявляется возле воды.

Зона № 4. Шоссейная дорога и прилегающие к ней поля. Здесь загрязнение незначительное, по всей территории в пределах 10 мкР/ч.

Зона № 5. Александровский карьер. Уровень излучения в норме, однако оно несколько выше, чем на нетронутых окружающих карьер грунтах.

Зона № 6. Село Шолохово, прилегающее с северовостока к г. Покров, река Базавлук. Измерения проходили вдоль шоссейной дороги, на мосту через реку, на окружающих полях. Средний радиационный фон несколько повышен, что связано с использованием здесь местных строительных метериалов. Максимальный фон был выявлен на мосту, произведенному из местных гранитов

Зона № 7. Северо-восточная граничная область поселка Рудник и прилегающая к нему часть Богдановского карьера. Общий радиационный фон незначительный. Измерения произведены вдоль дорог, на полях и возле карьера.

Зона № 8. Богдановский карьер (верхние пласты). Измерения фона осуществляли на поверхности карьера, не ниже глубин в 20 м.

Зона № 9. Богдановский карьер (глубокие области). В самой низшей точке изменения (50-55 м ниже поверхностного уровня), в точках, где проходит погрузка марганцевой руды, средний фон повышен и находится на уровне предельной нормы естественного излучения.

Зона № 10. Непосредственно поселок Рудник. Все измерения показали очень низкий радиационный фон 4 мкР/ч.

Зона № 11. Богдановская агломерационная фабрика. На территории найдены средние показатели фона, небольшое повышение связано с наличием систем обогащения руды и ее перевозкой. Также фабрика занимается изготовлением и использованием строительных материалов.

Зона № 12. Территория город Покров. Средний фон незначительный, в отдельных точках городов обнаружено его повышение, связанное с использованием гранита в памятниках и брусчатке.

Зона № 13. Чкаловская агломерационная фабрика. Территория включает шламохранилище. Некоторое повышение фона связано с использованием промышленных руд.

Зоны № 14 и № 15. Шевченковский карьер. Включает сельскохозяйственные поля. Средние показатели, которые несколько повышаются в отвалах. Однако в нижних частях карьера в местах выхода гранита (который взрывают в процессе его добычи) показатели выше нормы - 31 мкР/ч.

Зоны № 16 и № 17. Северный карьер и Чкаловский № 2. Средний фон в верхних частях карьеров находится в пределах от 17 до 21 мкР/ч, что является нормой, хотя он и выше, чем в других участках. В местах прямой добычи марганцевой руды в глубоких частях обоих карьеров радиационная обстановка достигает значений 34 мкР/ч.

Зоны № 18 и № 19. Чкаловский карьер № 1 (единственный карьер, который на сегодняшний день работает). На верхних участках фон достигает 17 мкР/ч, на его низших точках -34 мкР/ч.

Зона № 20. Территория Чкаловской обогатительной фабрики показала средний радиационный фон, который свойствен значениям в верхних частях карьеров по добыче ископаемых.

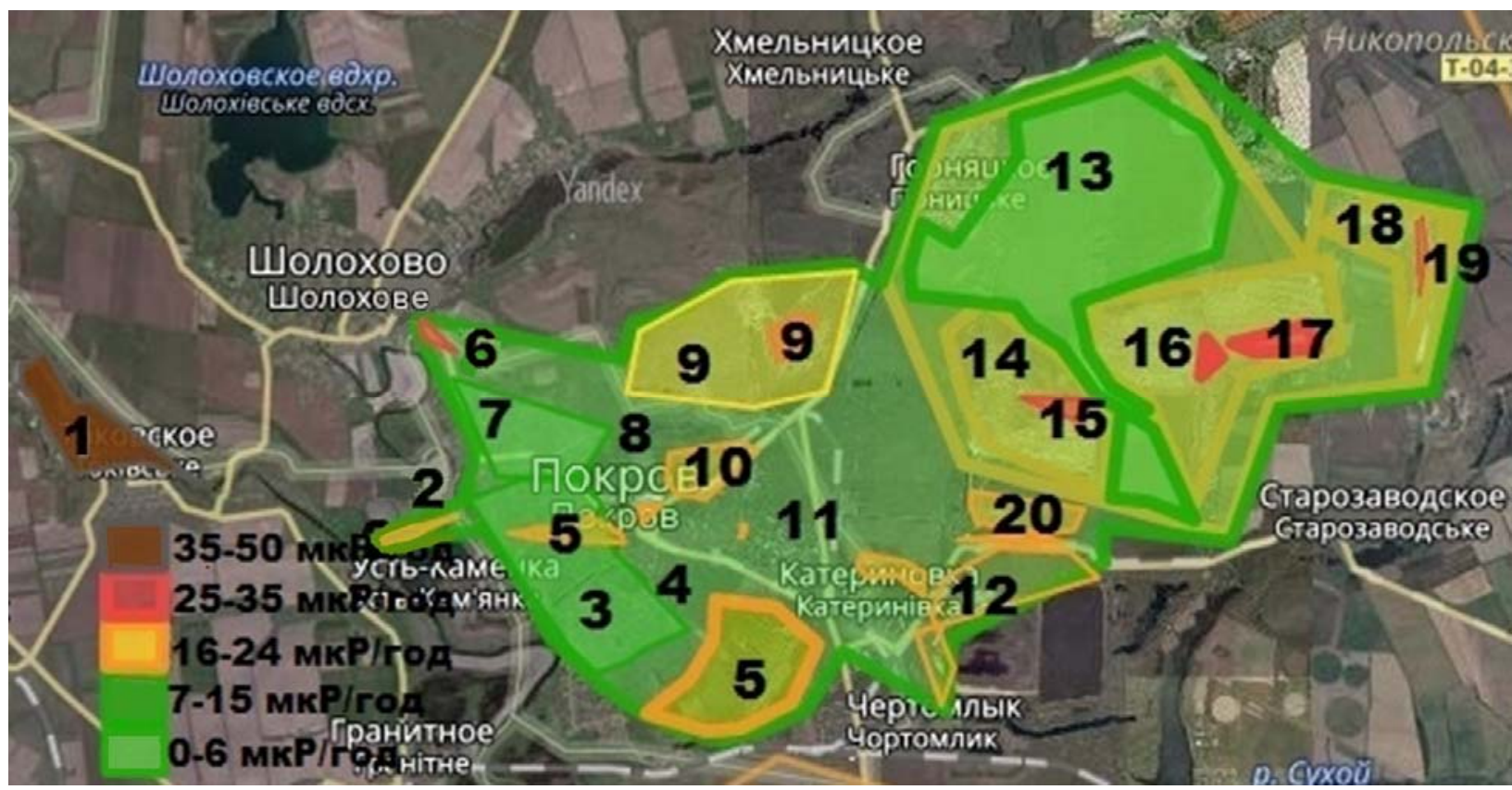

Рис. 1. Средний природный фон при обследовании г. Покров и прилегающих промышленных территорий

Исходя из промышленной ситуации (рис. 1), г. Покров окружен со всех сторон горнообогатительными предприятиями, а также набором горных выработок, образованных при добыче полезных ископаемых открытым способом. В этих зонах добываются марганцевые и сопряженные с ними руды, которые содержат природные радиоактивные элементы, обусловливающие появление фонового излучения в $\gamma$-диапазоне.

Если обогатительные фабрики находятся непосредственно на территориях г. Покров и прилегающих населенных пунктов, то выработки, карьеры и шламохранилища находятся на некотором удалении от 
населенных пунктов: минимальное расстояние - 1,5 км (для обогатительных комбинатов), максимальное - от 10 до 11 км (карьер Чкаловский № 1 на востоке и Токовский затопленный карьер - на западе). Как следствие, загрязнение природными радионуклидами, присутствующими в обрабатываемых горных породах, и определяет итоговые значения загрязнения на территории жилых районов г. Покров и его пригородов (поселков).

Крупнейший в Европе по запасам и в промышленном значении Никопольский марганцеворудный бассейн находится в русле рек Днепр, Молочная, у городов Никополь и Запорожье. В его состав входит Никопольское, Болышое Токмакское рудные месторождения, которые находятся в районе реки Ингулец, южнее Кривого Рога (рис. 2). Город Покров находится на границе зоны повышенной природной радиации, обусловленной выходами на поверхность полезных ископаемых (Gudkov, 2001).

Основной загрязнитель данной местности Орджоникидзевский горнообогатительный комбинат, расположенный в 10-15 км от г. Никополь, сырьевой базой комбината является Никопольское месторождение марганцевых руд. На базе упомянутого месторождения
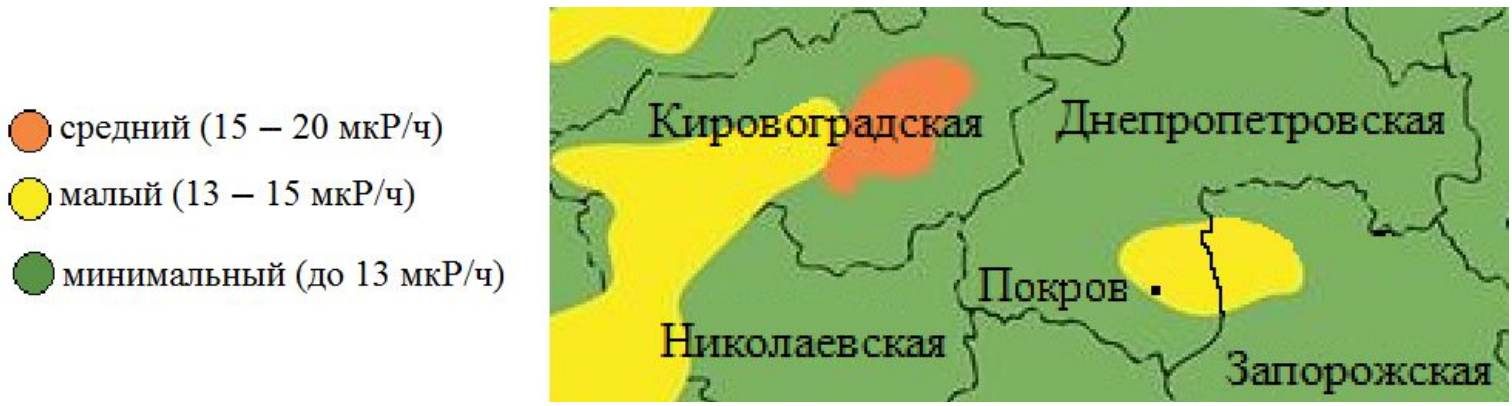

Рис. 2. Современный радиационный фон на территориях центральной Украины, прилегающих к Днепропетровской области (показано место расположения г. Покров)

эксплуатируются ряд карьеров: Александровский, Шевченковский, Богдановский, Запорожский, Покровский, Северный и Чкаловские № 1 и № 2. Никопольское марганцевое месторождение руды находится в соседстве с Криворожским железорудным бассейном, содержащим в грунте большое количество различных тяжелых металлов (Sherstyuk, 2012).

Продукция указанного Орджоникидзевского комбината - агломерат марганцевый, камень стеновой, песок закладочный, руда марганцевая обогащенная окислительно-карбонатная, сырье глинистое для производства керамзитового гравия и песка. Все указанные компоненты в той или иной степени содержат природные радиоактивные вещества.

Между городом и Богдановским карьером расположена основная промплощадка, на которой размещены Богдановские обогатительная и агломерационная фабрики. Еще одна действующая Чкаловская обогатительная фабрика расположена в 3 км к востоку от города на расстоянии 0,5 км от поселка Екатериновка. Александровская обогатительная фабрика находится на расстоянии 2 км к западу от города и 0,3 км южнее поселка Александровка. Все объекты (комбинаты) показали повышенные значения фона (20-25 мкР/ч), что связано, вероятно, со значительным пылеобразованием и отходами промобогащения.

На качественные показатели радиационного состояния почвы в районе г. Покров оказывают отрицательное влияние открытые горные работы, прежде всего в связи с изменением гидрологического режима, пыле- и газовыделением. Кроме того, горнотехническая и биологическая рекультивация выполняются в отдельных случаях с нарушением установленных требований.

Значительная часть указанных горнообогатительных предприятий отнесена к категории экологически опасных, поскольку они имеют в своем составе хвостохранилища, в которых в значительных объемах (от 16 до $400 \cdot 10^{6}$ м) накоплены шламы, содержащие железо, марганец, титан, уран. Поэтому в местах добычи марганцевой руды, а также на агломерационных фабриках и шламохранилищах присутствует повышенная концентрация радиационного излучения (в среднем от 17 до 31 мкР/ч).

Токовское гранитное месторождение, показавшее максимальный природный фон $\gamma$-излучения (до 50 мкР/ч), оценивается запасами красного гранита в 70 млн м ${ }^{3}$ и является одним из крупнейших в Украине: Токовский гранит твердый и долговечный, но при этом он используется только для внешней отделки, поскольку имеет второй класс радиоактивности.

Почвы местных рекультивированных участков имеют весьма незначительные уровни радиозагрязнения (7-10 мкР/ч), аналогичные значения обнаружены на залегающих здесь черноземах, используемых в сельском хозяйстве.

Территория города Покров составляет 2,6 тыс. га и состоит из самого города и пригородов: Чертомлык, Горняцкое, Горняк, Рудник. Радиационный фон в этих объектах определяется расстоянием до обогатительных фабрик, шламохранилищ и карьеров, поэтому уровни фона здесь отличаются в 2-3 раза, но в целом указанный уровень безопасный (17-20 мкР/ч). Несколько повышенные значения излучений (до 30-35 мкР/ч) в жилых зонах наблюдаются в местах концентраций пыли от транспорта - на дорогах, мостах, что соответствует предложенным гигиеническим оценкам загрязнения территорий города радиоактивными веществами техногенного происхождения (Okhrimenko et al., 2016).

Следует отметить, что в настоящее время в достаточной мере разработаны критерии оценки степени промышленного радиационного загрязнения окружающей среды. Разработанная и действующая в настоящее время система природоохранных критериев (например, предельно допустимые концентрации, предельно допустимые выбросы и сбросы загрязняющих веществ) техногенной среды должна учитывать и возможности постоянного переноса радиоизотопов на значительные территории, не имеющие отношения к горнообогатительным и металлургическим предприятиям (Kornilovich, 2006).

Определенную проблему населению и экосистемам степной зоны Украины (в первую очередь Каховского водохранилища) могут представлять воды реки Базавлук, которые насыщены радиоизотопами от гранитных пород, приходящихся на Токовские каскады водосбросов. Соответственно для реки Днепр важна геоинформационная методология анализа радиационного загрязнения речных систем (Polishchuk et al., 2005), поскольку в итоге указанные процессы негативно влияют на состояние воды и водной биоты данного региона (Ananieva et al., 2016).

\section{Выводы}

На основании проведенных измерений и оценки радиационного фона в типичных горнообогатительных 
агломерациях Днепропетровской области можно сделать ряд выводов.

Наибольшее радиационное загрязнение в исследуемом районе отмечено на территории Токовских водосбросов, где расположены затопленные карьеры по добыче красных гранитов (50 мкР/ч и выше).

Территории всех работающих карьеров проявляют повышенный радиационный фон (17-21 мкР/ч), причем на их нижних горизонтах отмечены максимальные значения (30-35 мкР/ч). Такое повышение связано с небольшими выходами гранита на некоторых пластах, а также местах прямой добычи марганцевой руды.

На горнообогатительных фабриках и шламохранилищах отмечено небольшое повышение фона относительно жилых территорий (от 13 до 20 мкР/ч), но все-таки он остается на допустимом уровне, который не влияет на работающее здесь население города.

Радиационный фон на территории города Покров, прилежащих сел, рекультивированных земель и на сельскохозяйственных полях имеет низкий уровень (5-7 мкР/ч). В ряде точек города (дороги и мост через реку Базавлук, памятники) обнаружено загрязнение на уровне 10-15 мкР/ч, что связано с использованием при их строительстве местных природных материалов. Поэтому общую радиационную ситуацию на территории города Покров и агломерации горнообогатительных предприятий на данный момент по современным критериям можно оценить как удовлетворительную.

\section{References}

Ananieva, T. V., Fedonenko, E. V., Shapovalenko, Z. V. (2016). Vklad radioekologicheskogo faktora v sostoyaniye metabolizma ryb transformirovannogo vodoyema [Contribution of the radioecological factor to the metabolism of fish in a transformed water bodies]. Biodiversity after the Chernobyl accident: The scientific proceed. of the Int. network AgroBioNet. Slovak Univ. Agricult., Nitra, Part II, 15-19 (in Russian).

Gablin, V. A., Ermakov, A. I., Kashirin, I. A. (2005). Sravnitelnaja otsenka rezultatov izmerenij radiatsionnih parametrov gruntov i pochv $\mathrm{s}$ uchastkov radiatsionnogo zagrjaznenija [Comparative evaluation of the results of measurements of radiation parameters of soils and soils from radiation contamination sites]. ANRI, 1, 49-55 (in Russian).

Galperin, M. L. (2012). Obshaja ecologija [General ecology]. Forum, Moscow (in Russian).

Gudkov, I. M. (2001). Suchasna radiatsijna obstanovka v Ukraini ta dejaki problemi radiologishnoji osviti v agrarnih navchalnih zakladah [Modern radiation situation in Ukraine and some problems of radiological education in agrarian educational institutions]. Agrarian science and education, 2(3-4), 5-13 (in Ukrainian).

Kharchenko, M. A. (2011). Radiatsija. Nevidimij ubijtsa [Radiation. The invisible killer]. Fenix, Rostov-na-Donu (in Russian).
Kovalenko, G. D., Voloshin, V. S. (2010). Osnovi radiatsionnoj ekologii [Fundamentals of radiation ecology]. Renata, Mariupol (in Ukrainian).

Kornilovich, B. J. (2006). Dejaki aspekti rozvitky prikladnoj radiohimiji $\mathrm{i}$ radioekologii [Some aspects of the development of applied radiochemy and radioecology]. Ukr. Chemical J., 72(5), 3-11 (in Ukrainian).

Landa, E. R. (2004). Uranium mill tailings: nuclear waste and natural laboratory for geochemical and radioecological investigations. J. Environ. Radioact., 77, 1-27.

Lebedev, V. V. (2012). Radiatsionnoe zagrjaznenie territorii zolotoserebrjannogo mestorojdenie «Klen» [Radiation contamination of the territory of the golden silver field «Klen»]. Bulletin Moscow State Univ. Series Natural Sci., 5, 94-97 (in Russian).

Ochrimenko, S. E., Korenkov, I. P., Akopova, N. A., Ivanov, S. I. (2016). Gigienisheskaja otsenka zagrjaznenija territorij goroda redioaktivlimi veschestvami tehnogennogo proishogdenija [Hygienic estimation of the pollution of the city's areas with radioactive substances of technogenic origin]. ANRI, 3(86), 64-71 (in Russian).

Polischuk, J. M., Peremitina, T. O., Kochergin, G. F. (2005). Geoinformatsionnaja metodologija rediatsionnogo zagrjaznenija rechnih sistem [Geoinformation methodology for the analysis of radiation contamination of river systems]. Problems of risk analysis, 2(3), 208-220 (in Russian).

Rjabseva, A. S. (2015). Radiatsionnoe zagrjaznenie territorii Rossii i jejo regionov [Radiation pollution of the territories of Russia and its regions]. Economics and management of innovative technol., 3, 167-171 (in Russian).

Romashova, L. A., Nikolaeva, O. N., Volkova, O. A. (2012). Priminenije kartograficheskogo metoda $\mathrm{v}$ izutcenii $\mathrm{i}$ reshenii problem radiatsionnogo zagrjaznenija territorij [Application of the cartographic method in studying and solving problems of radiation contamination of territories]. Inter-Expo Geo-Siberia, 3, 187-192 (in Russian).

Sherstyuk, N. P., Khilchevsky, V. K. (2012). Osobennosti gidrohimicheskih processov $\mathrm{v}$ tehnogennih $\mathrm{i}$ prirodnih vodnih objectah Krivbasa [Features of hydrochemical processes and technogenic and natural water bodies of Krivbass]. Akcent, Dnipropetrovsk (in Russian).

Sokolov, P. Ed. (2005). Kontrol radiatsionnogo zagrjaznenija okrujauchej sredi ot pilevih vibrosov, nadejnoct i dolgovechnost stroitelnah materialov, konstruktsij i osnovanij fundamentov [Control of radiation pollution of the environment from dust emissions reliability and durability of building materials, structures and bases of foundations]. Proc. IV Intern. Sci. and Tech. Conf. (Volgograd, 2005), Volgograd, Volgograd State Architec. and Construction Univ., 174-176 (in Russian).

Vishnyakov, A. A., Mishnev, A. I. (2013). Rentgenmetrradiometr DP-5: otdelnie problemi ecspluatatsii i puti ih reshenija [X-ray radiometer-DP-5: specific problems of operation and ways to solve them]. Technospheric safety, $1,21-25$ (in Russian). 